\title{
ENFRENTAMENTO DOS FAMILIARES DURANTE O TRABALHO DE PARTO PREMATURO
}

\section{$\underline{\text { Emily da Cruz Lima }}{ }^{1}$; Erika Anny Costa Cerqueira ${ }^{2}$; Shirlene Cerqueira dos $\operatorname{Santos}^{3}$ e Luciano Marques dos Santos ${ }^{4}$}

1. Graduanda em enfermagem. Universidade Estadual de Feira de Santana, e-mail: emilylima18@hotmail.com.

2. Graduanda em enfermagem. Universidade Estadual de Feira de Santana, e-mail: erikacerqueira12@gmail.com.

3. Graduanda em Enfermagem. Universidade Estadual de Feira de Santana, e-mail: shirlene_cerqueira@hotmail.com.

4. Orientador. Departamento de Saúde. Universidade Estadual de Feira de Santana, email: lucmarxenfo@yahoo.com.

PALAVRAS-CHAVES: Enfermagem. Trabalho de Parto Prematuro. Família

\section{INTRODUÇÃO}

A gestação é um processo que interfere em todos os aspectos da vida da mulher e de todas as pessoas envolvidas neste momento mágico. Este período é marcado por uma série de alterações físicas, psicológicas e por um turbilhão de sentimentos, sonhos e expectativas em relação a um período gestatório a termo e ao nascimento de um filho saudável, com características conforme as imaginadas e desejadas, sendo o momento do parto esperado por toda a família (CARVALHO et al., 2009; CUNHA et al., 2009;).

No entanto, diversos fatores podem interferir no curso normal dessa gravidez e a gestante pode ter que enfrentar um trabalho de parto prematuro (TPP), causando repercussões psicológicas para a ela e seus familiares, que somente eles podem definir. Essa vivência de uma gestação de risco e parto prematuro provocam sentimentos como frustração, impotência, culpa, insegurança e medo principalmente diante da possibilidade de sequelas ou óbito do seu recém-nascido (CUNHA et al., 2009).

Frente às complicações gestacionais que desencadeiam um TPP, a família vivencia momentos de dificuldades. Alguns relatos referem que os momentos de maior medo e ansiedade são decorrentes das adversidades dos serviços de saúde, como, por exemplo, a deficiência dos serviços de saúde diante das complicações da gestação, a falta de leitos na UTI neotanal e a deficiência médico-hospitalar, demonstrando que os estabelecimentos de saúde nem sempre estão preparados para o atendimento às intercorrências durante a gestação. Isto faz com que a parturiente e seus familiares precisem se deslocar de uma instituição de saúde para outra em busca de assistência (ARRUDA; MARCON, 2010).

Contatou-se nesse estudo uma incipiente produção do conhecimento tanto na literatura nacional quanto na internacional acerca das experiências da família durante o trabalho de parto prematuro. Isto posto, questiona-se: como é a experiência da família durante o trabalho de parto prematuro? 
O objetivo desse estudo é descrever a experiência da família durante o trabalho de parto prematuro. Este estudo é de grande relevância, pois fornece fundamentações teóricas importantes para melhor compreensão e enfretamento da família frente a um Trabalho de Parto Prematuro.

\section{METODOLOGIA}

Trata-se de um estudo do tipo qualitativo, descritivo e exploratório. Vinculado à pesquisa multicêntrica "Parto prematuro: estudo dos fatores associados para construção de estratégias de prevenção". Apresentaram-se como campo de pesquisa dois hospitais públicos do município de Feira de Santana, na Bahia.

Participaram do estudo 23 familiares de puérperas que tiveram trabalho de parto prematuro no período de março a julho de 2016, sendo adotado como critério para o encerramento da coleta a saturação teórica dos mesmos. Foram adotados como critérios de inclusão: familiares de puérperas que tiveram parto entre 20 e 36 semanas e 6 dias de gestação e o concepto pesando mais que 500 gramas; não apresentar problemas clínicos e obstétricos; ter condições psicológicas para as entrevistas. Não foi adotado nenhum critério de exclusão.

Antes da coleta do material empírico foi realizado o levantamento do estado da arte e sua análise, do período de 2009 à 2016. As bases de dados utilizadas foram: Science Direct, Base de dados de enfermagem, e National Library of Medicine. Sendo selecionados 18 artigos para os fins deste estudo.

Para coleta dos dados foi utilizada a entrevista semiestruturada. A análise dos dados foi realizada de acordo com o método de análise temática, que é uma das fases da Análise de Conteúdo preconizada por Bardin (2011), onde o tema é o conceito central.

Foi entregue aos sujeitos da pesquisa o Termo de Consentimento Livre e Esclarecido (TCLE). As informações fornecidas pelos participantes permaneceram confidenciais e o anonimato dos mesmos foi mantido através do uso de nomes (códigos: F01, F02, F03), sendo "F" referente ao familiar e 01, 02, etc., como a quantidade e ordem das entrevistas realizadas.

Este estudo atendeu os princípios éticos da resolução $n^{\circ}$ 466/2012, de 12 de dezembro de 2012 do Conselho Nacional de Saúde que envolvem as pesquisas com seres humanos. Foi aprovado pelo Comitê de Ética e Pesquisa da Universidade Federal do Rio Grande (FURG) através do Parecer de número 134/2013 e da Universidade Estadual de Feira de Santana (UEFS), através do Parecer de número 643.668.

\section{RESULTADOS E DISCUSSÃO}

O levantamento do estado da arte e sua análise foram realizados entre março e junho de 2016. No total, foram selecionados e lidos na íntegra, 18 artigos, que não tratam especificamente da temática abordada neste estudo, mas retratam aspectos das experiências vividas pelos familiares durante o TPP.

A análise das entrevistas permitiu compreender a experiências de familiares durante o trabalho de parto prematuro, identificar os sentimentos vivenciados e os desafios enfrentados. Nesse processo, foram identificadas quatro categorias: Vivenciando momentos inicialmente inesperados; Sofrendo durante o TPP intra-hospitalar; Tendo fé em Deus; Sentindo-se aliviados após o parto.

Na primeira categoria foi possível perceber que a experiência dos familiares é iniciada com a identificação dos sinais e sintomas apresentados pelas gestantes, como dor e rompimento da bolsa das águas, mas que não são traduzidos pelos familiares como o inicio do TPP, tal desconhecimento pode estar associado a alguns fatores como falta de informações fornecidas para a família durante sessões de educação em saúde na atenção pré-natal, não participação durante esta atenção, e também devido à ausência de avaliação da estratificação 
do risco obstétrico para este evento no transcurso gestacional pelos trabalhadores da saúde responsáveis pela atenção pré-natal.

Os resultados encontrados no presente estudo reforçam os encontrados também no estudo de Pohlmann et al. (2016) que afirmam a necessidade de uma atenção básica e de toda rede de saúde mais eficiente para a prevenção da prematuridade e para o fornecimento de mais informações às gestantes e seus familiares, o que poderia evitar o desconhecimento dos mesmos acerca dos sinais e sintomas do TPP.

$\mathrm{Na}$ vigência dos sinais e sintomas a família se reorganiza para poder ajudar a gestante na tentativa de resolver a situação vivenciada. Assim, a família mobiliza-se na busca por atenção hospitalar para tentar resolver os sinais e sintomas apresentados pela sua familiar, vivenciando o fenômeno de peregrinação por leito obstétrico. Este momento apareceu na experiência familiar em virtude da ausência de articulação entre a atenção primária e hospitalar, principalmente do sistema de referência e contra referência.

Após conseguir leito obstétrico para a hospitalização da gestante e de ter sido diagnosticado o TPP, a família vivencia um momento inesperado que a mobiliza de forma muito intensa no seu domínio afetivo, marcado pelo rompimento de sua ideia de que a gestação chegaria ao termo. Este momento foi marcado por sentimentos como frustação, medo do desconhecido, impotência, culpa, insegurança, susto, culpa, angustia e profunda tristeza.

Assim, a família inicia outro momento da experiência de acompanhamento do TPP, onde ao receber o diagnostico desta situação, a mesma entra na experiência hospitalar vivenciado o sentimento de vulnerabilidade.

De acordo com Pettengill e Angelo (2005) a vulnerabilidade familiar em uma situação de doença e hospitalização de um membro da familia traz para ela uma sensação de ameaça a sua autonomia, decorrente do excesso de demandas que aparecem nessas situações dificultando sua capacidade para lidar e agir frente a estes acontecimentos, gerando incerteza, impotência e medo do desfecho.

Diante da ausência de informações sobre o que estava acontecendo com a parturiente, eles se mobilizam a acionar suas crenças de que algo de errado poderia acontecer, destacandose o medo de complicações para a parturiente e o seu concepto que poderiam culminar com a morte do recém-nascido ou da mulher, sendo este momento marcado por intensa pressão emocional, que desencadeou sentimentos como tristeza, tensão, nervosismo e susto.

A espera por informações do lado de fora do centro cirúrgico é considerado um momento de extrema tensão, pois se torna marcante o medo de repercussões negativas do parto.

Neste momento, os familiares consideram o suporte e a atenção fornecida pela equipe de saúde como despreparada, carente e até hostil, onde os mesmos relatam sobre a falta de informações durante o período de espera, já que em muitos hospitais estes não podem permanecer no centro obstétrico durante o trabalho de parto do seu familiar, tornando esta experiência ainda mais traumática. Porém, a Lei $n^{\circ} 11.108$, promulgada em 7 de abril de 2005, afirma o direito da mulher em ter um acompanhante de sua escolha durante o pré-natal e todas as fases de internação para o parto, incluindo os períodos do trabalho de parto, parto e pós-parto (BRASIL, 2005).

Durante toda essa experiência repleta de sentimentos negativos e traumatizantes, a fé em um Ser Supremo foi utilizada como principal instrumento de suporte dos familiares que utilizaram suas crenças como fonte de conforto e esperança de que esse momento traumático terminaria bem para a parturiente e seu filho e com o nascimento de uma criança saudável e sem complicações.

O final da experiência do TPP foi então marcado pelo alivio do sofrimento vivenciado pela família, ao saber que a parturiente estava em boas condições de saúde e que o recém- 
nascido poderia sobreviver mesmo que tivesse sido hospitalizado na Unidade de tratamento intensivo, marcando assim o fim da situação de desespero.

\section{CONSIDERAÇÕES FINAIS}

Diante do contexto investigado, fica claro no estudo um déficit de informações e uma carência na rede de saúde, indicando a importância de um atendimento de qualidade e eficiente. Os familiares devem receber suporte para que possam enfrentar essa situação da melhor forma possível. É necessário melhorar a articulação entre a atenção primaria e a hospitalar no município. Também se faz necessárias melhoras na estrutura das unidades obstétricas. Conclui-se assim, que a família deve ser incluída como um cliente em potencial durante a atenção pré-natal, considerando a mesma como a primeira unidade básica de cuidados de seus membros durante a experiência de adoecimento. Os trabalhadores da atenção primária em saúde precisam reforçar a crença de que a família é uma constante na vida da gestante. Por isso, faz-se necessário compreender os significados da experiência do TPP para a família e assim, identificar os sentimentos vivenciados durante este processo, suas forças, rede de apoio e suporte social, para que problemas afetivos, cognitivos e comportamentais possam ser identificados pelos trabalhadores da saúde das unidades obstétricas e intervenções possam ser implementadas para assim, o familiar ser contemplado em suas demandas de cuidado. A identificação e utilização das forças da família e de sua rede de apoio e suporte social devem ser incluídas como estratégias para o seu cuidado intra-hospitalar. Tornou-se evidente também a importância de maiores números de publicações acerca desta temática, para que se possa ressaltar o papel da família como principal rede de apoio, juntamente com a religião, no enfrentamento de um Trabalho de Parto Prematuro, ressaltando a importância desse estudo em trazer o papel da família nesta experiência, já que para eles esse também é um momento especial e que pode terminar sendo traumático.

\section{REFERÊNCIAS}

ARRUDA, D. C.; MARCON, S. S. Experiência da família ao conviver com sequelas decorrentes da prematuridade do filho. Rev Bras Enferm, Brasília 2010 jul-ago; jul-ago; 63(4): 595-602.

BARDIN, L. Análise de conteúdo. São Paulo: Edições 70, 2011. 279 p.

BRASIL. Lei No 11.108, de 7 de abril de 2005. Dispõe sobre a garantia às parturientes o direito à presença de acompanhante durante o trabalho de parto, parto e pós parto imediato, no âmbito do Sistema Único de Saúde - SUS. Diário Oficial da República Federativa do Brasil, 8 abril 2005. Seção 1

CARVALHO, B.R et al. Inibição do trabalho de parto pré-termo: vivência de mulheres. Cienc Cuid Saude 2009 Out/Dez; 8(4):540-547

CUNHA, E. F. C et al. ASPECTOS SÓCIOEMOCIONAIS DE MÃES DE BEBÊS PREMATUROS. Psicologia em foco, Aracaju, Faculdade Pio Décimo, v. 3, n. 2, jul./dez. 2009.

PETTENGILL, M.A.M; ANGELO, M. Vulnerabilidade da família: desenvolvimento do conceito. Rev Latino-am Enfermagem 2005 novembro-dezembro; 13(6):982-8

POHLMANN, F. C. et al. Parto prematuro: enfoques presentes en la producción científica nacional e internacional. Enfermería global, abril-2016. 